\title{
THE APPROXIMATION OF CES TYPE FUNCTIONS: A REPLY*
}

\begin{abstract}
BY Ј。KMENTA
AN INEVITABLE IMPLICATION of using a function $f_{1}$ as an approximation to another function $f_{2}$ is that $f_{1}$ is also an approximation to functions other than $f_{2}$. This is obvious and hardly relevant; what is relevant is how well $f_{1}$ approximates $f_{2}$ within some range of practical importance. With respect to the approximation to the CES function given by equation (2) in Dr. McCarthy's paper, the calculations which I have done indicate that the error of approximation tends to be relatively small except for cases in which extreme values of the elasticity of substitution are combined with extreme values of input ratios. Similar results have been obtained by $\mathrm{H}$. Thornber in a recent Monte Carlo experiment. In that study the author compares several estimators of elasticity of substitution, including one based on our approximation, to the CES function. ${ }^{1}$

The main part of Dr. McCarthy's paper is concerned with demonstrating that equation (2), intended to be used as an approximation to the CES function, could equally well be considered as an approximation to a whole class of production functions of which the CES function is a special case. It is not clear why this should be troublesome as long as equation (2) provides a good approximation to the CES function. The purpose of equation (2) is to simplify - at the cost of some loss of precision-the problem of estimating the parameters of the CES function. This purpose will be satisfied if the approximation is a satisfactory one.

The main objection of Dr. McCarthy is that the use of the approximate version of the CES function affects the proper evaluation of statistical tests of significance. This is certainly true; it is a part of the price of using an approximation in place of the true function. But the seriousness of the specification error depends on the degree of closeness of approximation and, as emphasized at the outset, it is this aspect which is relevant and deserves attention.
\end{abstract}

Michigan State University, U.S.A.

* Manuscript received January 17, 1967.

1 See H. Thornber, "The Elasticity of Substitution: Properties of Alternative Estimators," mimeographed paper, University of Chicago Econometrics Workshop, February 1966; also presented at the Econometric Society annual meeting in San Francisco, December 1966. 